$\begin{array}{ll}\text { Research Square } & \begin{array}{l}\text { Preprints are preliminary reports that have not undergone peer review. } \\ \text { They should not be considered conclusive, used to inform clinical practice, } \\ \text { or referenced by the media as validated information. }\end{array}\end{array}$

\title{
Association of accumulated number of underweight with occurrence of tuberculosis
}

\author{
Ga Eun Park \\ Konkuk University of Medical Center, Konkuk University School of Medicine \\ Hyun Kyun Ki \\ Konkuk University of Medical Center, Konkuk University School of Medicine \\ Yeonghee Eun \\ Samsung Medical Center, Sungkyunkwan University School of Medicine \\ Kyungdo Han \\ Soongsil University \\ Hyungjin Kim ( $\sim$ passiondoc@gmail.com) \\ Samsung Medical Center, Sungkyunkwan University School of Medicine
}

\section{Research Article}

Keywords: Underweight, BMI, tuberculosis, Nationwide data

Posted Date: November 10th, 2021

DOI: https://doi.org/10.21203/rs.3.rs-993224/v1

License: @ (i) This work is licensed under a Creative Commons Attribution 4.0 International License. Read Full License 


\section{Abstract}

Underweight might be a risk factor of tuberculosis (TB), but the association between duration of underweight and occurrence of TB is inconclusive. The objective of this study was to determine whether there is a difference in occurrence of TB according to the cumulative number of underweight in an intermediate TB burden country. The National Health Insurance database was used. Eligible subjects were individuals without history of TB before 2006, and who underwent national health examination between January 2009 and 31 December 2010. Included individuals in the analysis were followed until 31 December 2017. Accumulated number of underweight was defined as the number of times recorded as underweight during the national health examination over four consecutive years. The primary outcome of the study was newly diagnosed TB according to accumulated number of underweight. Among a study population of 2,396,434, TB was identified in 9,322 (3.89\%) cases. A high accumulated number of underweight and low body mass index (BMI) level were significantly associated with occurrence of TB. This association remained consistent after adjusting for demographic factors and underlying diseases. In stratified analysis based on age, sex, diabetes (DM), hypertension (HTN), and waist circumference (WC) in metabolic syndrome (MS), the accumulated number of underweight was related consistently to occurrence of TB. A high accumulated number of underweight was associated with increased risk of TB.

\section{Introduction}

The World Health Organization (WHO) reported about 10 million new tuberculosis (TB) cases globally and approximately 1.7 million TB-related deaths worldwide in the year 2019 Vigorous infection control measures have been implemented over the decades, and the incidence and death rates were declining yearly. However, TB is still responsible for more than a million deaths each year, primarily in low-income countries ${ }^{1}$. The Republic of Korea (hereafter referred to as "Korea") has achieved remarkable success in economic growth with significant improvements in quality of life over the past decades. The TB problem in Korea, however, which emerged in the 1950s, is unresolved despite long-term strategic planning of the national TB control program. The number of TB patients has been decreasing for six consecutive years. In 2018, 26,433 new TB cases were reported, 1,728 fewer compared to the previous year. However, Korea still has the highest TB incidence rate and mortality rate among Organization for Economic Cooperation and Development (OECD) countries ${ }^{2,3}$.

Underweight or low body mass index (BMI) is an established risk factor for development of $\mathrm{TB}^{4-10}$. Undernutritional status, a proxy for underweight, can lead to progression from latent TB to active TB due to impairment of the cell-mediated immune system ${ }^{6-8}$. A more than three-fold increased risk of TB was noted in people with underweight or low BMI compared to those with normal body weight ${ }^{8}$. These studies had focused on an association between underweight or low

$\mathrm{BMI}$ at one time point and the occurrence of TB. However, the link between duration of underweight and occurrence of TB has not been studied. The aim of the present study was to determine whether there is a difference in the occurrence of TB according to the cumulative number of underweight based on data from national health examinations in Korea, which is as an intermediate TB burden country. In addition, the difference in occurrence of TB according to changes in body weight was analyzed.

\section{Results}

\section{Baseline characteristics of study populations.}

Of the 2,513,129 people who had undergone health examinations for four consecutive years prior to $2009,2,396,434$ eligible subjects were included in the analysis after exclusion (Figure 1). Baseline characteristics of the study population according to accumulated number of underweight are described in Table 1. There were 2,248,457 (93.8\%) subjects with zero accumulated number of underweight, 50,077 (2.08\%) subjects with one accumulated number of underweight, $28,559(1.19 \%)$ subjects with two accumulated number of underweight, 25,597 (1.06\%) subjects with three accumulated number of underweight, and 43,744

(1.82\%) subjects with four accumulated number of underweight. 
Table 1

Baseline characteristic of the study populations according to the accumulated number of being underweight.

\begin{tabular}{|c|c|c|c|c|c|c|}
\hline & \multicolumn{6}{|c|}{ Accumulated number of being underweight } \\
\hline & 0 & 1 & 2 & 3 & 4 & p value \\
\hline & $2248457(93.8)$ & $50077(2.08)$ & 28559 (1.19) & $25597(1.06)$ & $43744(1.82)$ & $<0.0001$ \\
\hline Age & $42.5 \pm 10.44$ & $37.25 \pm 10.77$ & $35.94 \pm 10.35$ & $35.27 \pm 10.06$ & $34.91 \pm 9.99$ & $<0.0001$ \\
\hline 20-39 & $1016130(45.19)$ & $33524(66.94)$ & $20523(71.86)$ & $19236(75.15)$ & 33418 (76.39) & \\
\hline $40-64$ & $1188218(52.85)$ & $15798(31.55)$ & $7663(26.83)$ & $6049(23.63)$ & $9803(22.41)$ & \\
\hline $65<$ & $44109(1.96)$ & $755(1.51)$ & $373(1.31)$ & $312(1.22)$ & $523(1.2)$ & \\
\hline Sex & & & & & & $<0.0001$ \\
\hline Male & 1722635 (76.61) & $23537(47)$ & $12016(42.07)$ & $10199(39.84)$ & 16720 (38.22) & \\
\hline Female & $525822(23.39)$ & $26540(53)$ & $16543(57.93)$ & $15398(60.16)$ & $27024(61.78)$ & \\
\hline Smoking & & & & & & $<0.0001$ \\
\hline Non & 986840 (43.89) & 30893 (61.69) & 18459 (64.63) & $16888(65.98)$ & $29400(67.21)$ & \\
\hline Ex & $463362(20.61)$ & $5134(10.25)$ & $2611(9.14)$ & 1964 (7.67) & 3040 (6.95) & \\
\hline Current & 798255 (35.5) & $14050(28.06)$ & 7489 (26.22) & 6745 (26.35) & $11304(25.84)$ & \\
\hline Drink & & & & & & $<0.0001$ \\
\hline Non & 846399 (37.64) & $24188(48.3)$ & 14259 (49.93) & $13031(50.91)$ & 22566 (51.59) & \\
\hline Mild & 1214930 (54.03) & 23561 (47.05) & 13157 (46.07) & $11528(45.04)$ & 19637 (44.89) & \\
\hline Heavy & 187128 (8.32) & $2328(4.65)$ & $1143(4)$ & 1038 (4.06) & 1541 (3.52) & \\
\hline Regular exercise & $472953(21.03)$ & $6243(12.47)$ & $2984(10.45)$ & $2496(9.75)$ & 3771 (8.62) & $<0.0001$ \\
\hline Low income (20\%) & $358515(15.94)$ & $6633(13.25)$ & $3400(11.91)$ & 2788 (10.89) & $4643(10.61)$ & $<0.0001$ \\
\hline DM & 164746 (7.33) & $1588(3.17)$ & $745(2.61)$ & $590(2.3)$ & $836(1.91)$ & $<0.0001$ \\
\hline HTN & 448078 (19.93) & 3389 (6.77) & $1500(5.25)$ & 1169 (4.57) & 1735 (3.97) & $<0.0001$ \\
\hline Dyslipidemia & 363881 (16.18) & $3155(6.3)$ & $1526(5.34)$ & $1357(5.3)$ & 1549 (3.54) & $<0.0001$ \\
\hline WC & $81.44 \pm 8.21$ & $69.97 \pm 6.32$ & $68.25 \pm 5.75$ & $67.37 \pm 5.79$ & $65.42 \pm 5.27$ & $<0.0001$ \\
\hline BMI & $24.04 \pm 2.88$ & $19.31 \pm 1.36$ & $18.7 \pm 0.93$ & $18.29 \pm 0.95$ & $17.35 \pm 0.77$ & $<0.0001$ \\
\hline \multicolumn{7}{|c|}{ Values with \pm symbols denote mean \pm standard deviation. } \\
\hline \multicolumn{7}{|c|}{ Data are expressed as number (\%) of subjects. } \\
\hline DM: diab & ITN: hyperten & C: waist cir & $\mathrm{ce} ; \mathrm{BMI}$ & mass ind & & \\
\hline
\end{tabular}

Those with a higher accumulated number of underweight appeared to be younger, more typically female, non-smokers, and non-drinkers. Those with a higher accumulated number of underweight also appeared to have exercised less frequently and have lower income. Those with a higher accumulated number of underweight tended to have fewer underlying diseases.

(Table 1)

Associations of BMI level and accumulated number of underweight with occurrence of TB. During a median follow-up of 7.27 years after a 1-year lag period, 9,322 (3.59\%) people were diagnosed with TB. We investigated the association between accumulated number of underweight and clinical outcomes and the association between BMI level and clinical outcomes. A high accumulated number of underweight and low BMI level were significantly associated with occurrence of TB. This association remained consistent after adjusting for demographic factors and underlying diseases (Table 2). The Kaplan-Meier estimations of the incidence probability of TB according to BMI level or accumulated number of underweight are shown in Figure 2. Notably, a higher cumulative incidence probability of TB rates was observed at both lower BMI level and higher accumulated number of underweight. 
Table 2

Hazard ratios (HR) and 95\% confidence intervals (CI) of occurrence of TB by BMI level or accumulated number of being underweight.

\begin{tabular}{|c|c|c|c|c|c|c|c|c|c|c|c|c|}
\hline & N. & TB & $\begin{array}{l}\text { Follow-up } \\
\text { Duration, } \\
\text { Person-year }\end{array}$ & $\begin{array}{l}\text { IR } \\
\text { per } \\
1000\end{array}$ & $\begin{array}{l}\text { Model 19, } \\
\text { HR } \\
(95 \% \mathrm{Cl})\end{array}$ & p-value & $\begin{array}{l}\text { Model } 2^{b} \text {, } \\
\text { HR } \\
(95 \% \mathrm{Cl})\end{array}$ & p-value & $\begin{array}{l}\text { Model 3c, } \\
\text { HR } \\
(95 \% \mathrm{Cl})\end{array}$ & p-value & $\begin{array}{l}\text { Model } \\
4^{d}, \mathrm{HR} \\
(95 \% \\
\text { Cl) }\end{array}$ & p-value \\
\hline \multicolumn{13}{|l|}{ BMI } \\
\hline$<18.5$ & 86071 & 749 & 607676.69 & 1.23256 & $\begin{array}{l}1.653 \\
(1.531- \\
1.785)\end{array}$ & $<0.0001$ & $\begin{array}{l}2.071 \\
(1.916- \\
2.238)\end{array}$ & $<0.0001$ & $\begin{array}{l}2.038 \\
(1.885- \\
2.202)\end{array}$ & $<0.0001$ & $\begin{array}{l}2.031 \\
(1.879- \\
2.196)\end{array}$ & $<0.0001$ \\
\hline$<23$ & 935457 & 4969 & 6662012.23 & 0.74587 & 1(Ref.) & & 1(Ref.) & & 1(Ref.) & & 1(Ref.) & \\
\hline$<25$ & 612871 & 1957 & 4382844.86 & 0.44651 & $\begin{array}{l}0.599 \\
(0.568- \\
0.631)\end{array}$ & & $\begin{array}{l}0.536 \\
(0.509- \\
0.565)\end{array}$ & & $\begin{array}{l}0.543 \\
(0.515- \\
0.572)\end{array}$ & & $\begin{array}{l}0.537 \\
(0.509- \\
0.566)\end{array}$ & \\
\hline$<30$ & 687574 & 1533 & 4912660.07 & 0.31205 & $\begin{array}{l}0.418 \\
(0.395- \\
0.443)\end{array}$ & & $\begin{array}{l}0.376 \\
(0.355- \\
0.398)\end{array}$ & & $\begin{array}{l}0.379 \\
(0.358- \\
0.402)\end{array}$ & & $\begin{array}{l}0.367 \\
(0.346- \\
0.389)\end{array}$ & \\
\hline $30<$ & 74461 & 114 & 528497.25 & 0.21571 & $\begin{array}{l}0.289 \\
(0.24- \\
0.348)\end{array}$ & & $\begin{array}{l}0.295 \\
(0.245- \\
0.355)\end{array}$ & & $\begin{array}{l}0.293 \\
(0.243- \\
0.353)\end{array}$ & & $\begin{array}{l}0.269 \\
(0.223- \\
0.324)\end{array}$ & \\
\hline \multicolumn{13}{|c|}{ Accumulated number of being underweight } \\
\hline 0 & 2248457 & 8154 & 16047688.45 & 0.50811 & 1(Ref.) & $<0.0001$ & 1(Ref.) & $<0.0001$ & 1(Ref.) & $<.0001$ & 1(Ref.) & $<.0001$ \\
\hline 1 & 50077 & 335 & 354086.38 & 0.9461 & $\begin{array}{l}1.86 \\
(1.668- \\
2.075)\end{array}$ & & $\begin{array}{l}2.278 \\
(2.04- \\
2.543)\end{array}$ & & $\begin{array}{l}2.236 \\
(2.003- \\
2.496)\end{array}$ & & $\begin{array}{l}2.208 \\
(1.978- \\
2.465)\end{array}$ & \\
\hline 2 & 28559 & 233 & 201932.53 & 1.15385 & $\begin{array}{l}2.269 \\
(1.992- \\
2.584)\end{array}$ & & $\begin{array}{l}2.934 \\
(2.573- \\
3.346)\end{array}$ & & $\begin{array}{l}2.879 \\
(2.524- \\
3.282)\end{array}$ & & $\begin{array}{l}2.84 \\
(2.49- \\
3.238)\end{array}$ & \\
\hline 3 & 25597 & 197 & 180870.79 & 1.08918 & $\begin{array}{l}2.141 \\
(1.859- \\
2.467)\end{array}$ & & $\begin{array}{l}2.848 \\
(2.47- \\
3.284)\end{array}$ & & $\begin{array}{l}2.783 \\
(2.413- \\
3.209)\end{array}$ & & $\begin{array}{l}2.743 \\
(2.379- \\
3.164)\end{array}$ & \\
\hline 4 & 43744 & 403 & 309112.94 & 1.30373 & $\begin{array}{l}2.563 \\
(2.319- \\
2.833)\end{array}$ & & $\begin{array}{l}3.46 \\
(3.125- \\
3.831)\end{array}$ & & $\begin{array}{l}3.378 \\
(3.051- \\
3.74)\end{array}$ & & $\begin{array}{l}3.326 \\
(3.004- \\
3.684)\end{array}$ & \\
\hline \multicolumn{13}{|c|}{ TB: tuberculosis; IR: incidence rate; HR: hazard ratio; Cl: confidence interval; BMI: body mass index. } \\
\hline \multicolumn{13}{|c|}{ aModel 1: Non-adjusted. } \\
\hline \multicolumn{13}{|c|}{ bModel 2: adjusted for age and sex. } \\
\hline
\end{tabular}

Stratified analysis of the covariates on the association between BMI or accumulated number of underweight and occurrence of tuberculosis. The potential impact of other independent factors on the association of accumulated number of underweight with occurrence of TB was evaluated by stratified analysis. When we performed stratified analysis according to age, sex, DM, HTN, and WC in metabolic syndrome (MS), only age and sex were effect modifiers, and the trend in the association of accumulated number of underweight and occurrence of TB remained unchanged (Table 3). 
Table 3

The association of accumulated number of being underweight with occurrence of tuberculosis stratified by various independent factors.

Accumulated number of being underweight
N.

TB
Duration
IR per
Estimated HR

$(95 \% \mathrm{Cl})$ $p$-value $p$ for interaction

Age

20-39 0

2

3

$\frac{3}{4}$

40-64 0

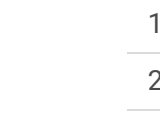

1

2

3

4

$65 \leq \quad 0$

1

2

3

4

Sex

Male $\quad 0$

0
1

3

4

Female 0

\section{1}

2

3

4

DM

No $\quad 0$

0

\section{1}

2

3

4

Yes

0
1

2

3

4

$$
\begin{aligned}
& 1016 \\
& 3352 \\
& 2052 \\
& 1923 \\
& 3341 \\
& \hline
\end{aligned}
$$

\begin{tabular}{l}
1016 \\
3352 \\
2052 \\
1923 \\
3341 \\
\hline
\end{tabular}

\begin{tabular}{ll}
33418 & 225 \\
\hline 1188218 & 4893
\end{tabular}

1016130
33524

15798

7663

6049

147

6049

101

44109

63

$755 \quad 26$

$373 \quad 15$

31210

$523 \quad 18$

\begin{tabular}{lllllll}
1722635 & 6330 & 12313526.09 & 0.51407 & 1 (Ref.) & $<0.0001$ & $<0.0001$ \\
\hline 23537 & 214 & 165917.89 & 1.28979 & $2.534(2.211-2.905)$ & & \\
12016 & 151 & 84597.6 & 1.78492 & $3.568(3.035-4.195)$ & \\
10199 & 111 & 71655.97 & 1.54907 & $3.08(2.551-3.717)$ & \\
16720 & 219 & 117699.64 & 1.86067 & $3.694(3.226-4.23)$ & \\
\hline 525822 & 1824 & 3734162.36 & 0.48846 & $1($ Ref. $)$ & \\
\hline 26540 & 121 & 188168.49 & 0.64304 & $1.464(1.214-1.765)$ & \\
\hline 16543 & 82 & 117334.93 & 0.69885 & $1.624(1.297-2.034)$ & \\
\hline 15398 & 86 & 109214.82 & 0.78744 & $1.852(1.486-2.31)$ & \\
\hline 27024 & 184 & 191413.3 & 0.96127 & $2.271(1.939-2.66)$ &
\end{tabular}

\begin{tabular}{lllllll}
2083711 & 7009 & 14887011.91 & 0.47081 & 1 (Ref.) & $<0.0001$ & 0.084 \\
\hline 48489 & 319 & 343191.48 & 0.92951 & $2.245(2.004-2.514)$ & & \\
27814 & 213 & 196854.41 & 1.08202 & $2.726(2.376-3.128)$ & \\
25007 & 190 & 176838.16 & 1.07443 & $2.768(2.393-3.202)$ & \\
42908 & 381 & 303475.62 & 1.25546 & $3.252(2.928-3.613)$ & & $<0.0001$ \\
164746 & 1145 & 1160676.55 & 0.98649 & 1 (Ref.) & \\
1588 & 16 & 10894.9 & 1.46858 & $1.477(0.901-2.422)$ & \\
745 & 20 & 5078.12 & 3.93846 & $4.237(2.719-6.603)$ & \\
590 & 7 & 4032.62 & 1.73584 & $1.807(0.859-3.802)$ & \\
836 & 22 & 5637.32 & 3.90256 & $4.071(2.664-6.22)$ &
\end{tabular}

HTN

TB: tuberculosis; IR: incidence rate; HR: hazard ratio; Cl: confidence interval; DM: diabetes mellitus; HTN: hypertension; WC: waist circumference; MS: metabolic syndrome. 


\begin{tabular}{|c|c|c|c|c|c|c|c|c|}
\hline & $\begin{array}{l}\text { Accumulated number of being } \\
\text { underweight }\end{array}$ & N. & TB & Duration & $\begin{array}{l}\text { IR per } \\
1000\end{array}$ & $\begin{array}{l}\text { Estimated HR } \\
(95 \% \mathrm{Cl})\end{array}$ & p-value & $\begin{array}{l}\mathrm{p} \text { for } \\
\text { interaction }\end{array}$ \\
\hline \multirow[t]{5}{*}{ No } & 0 & 1800379 & 6203 & 12869752.79 & 0.48198 & 1(Ref.) & $<0.0001$ & 0.0599 \\
\hline & 1 & 46688 & 298 & 330517.49 & 0.90162 & $2.129(1.894-2.395)$ & & \\
\hline & 2 & 27059 & 209 & 191559.24 & 1.09105 & $2.68(2.332-3.08)$ & & \\
\hline & 3 & 24428 & 186 & 172786.48 & 1.07647 & $2.699(2.329-3.127)$ & & \\
\hline & 4 & 42009 & 366 & 297239.81 & 1.23133 & $3.105(2.788-3.458)$ & & \\
\hline \multirow[t]{5}{*}{ Yes } & 0 & 448078 & 1951 & 3177935.66 & 0.61392 & 1(Ref.) & $<0.0001$ & \\
\hline & 1 & 3389 & 37 & 23568.89 & 1.56987 & $2.386(1.723-3.305)$ & & \\
\hline & 2 & 1500 & 24 & 10373.29 & 2.31363 & $3.667(2.45-5.489)$ & & \\
\hline & 3 & 1169 & 11 & 8084.3 & 1.36066 & $2.073(1.145-3.751)$ & & \\
\hline & 4 & 1735 & 37 & 11873.13 & 3.11628 & $4.932(3.558-6.838)$ & & \\
\hline \multicolumn{9}{|c|}{$\begin{array}{l}\text { WC } \\
\text { in MS }\end{array}$} \\
\hline \multirow[t]{5}{*}{ No } & 0 & 1860853 & 7111 & 13289090.35 & 0.5351 & 1(Ref.) & $<0.0001$ & 0.4696 \\
\hline & 1 & 49608 & 334 & 350754.51 & 0.95223 & $2.08(1.862-2.323)$ & & \\
\hline & 2 & 28412 & 232 & 200883.64 & 1.1549 & $2.656(2.328-3.03)$ & & \\
\hline & 3 & 25415 & 196 & 179573.13 & 1.09148 & $2.565(2.223-2.959)$ & & \\
\hline & 4 & 43713 & 402 & 308893.74 & 1.30142 & $3.111(2.808-3.446)$ & & \\
\hline \multirow[t]{5}{*}{ Yes } & 0 & 387604 & 1043 & 2758598.1 & 0.37809 & 1(Ref.) & 0.0105 & \\
\hline & 1 & 469 & 1 & 3331.87 & 0.30013 & $0.999(0.141-7.104)$ & & \\
\hline & 2 & 147 & 1 & 1048.9 & 0.95338 & $5.246(0.735-37.426)$ & & \\
\hline & 3 & 182 & 1 & 1297.66 & 0.77062 & $5.286(0.738-37.854)$ & & \\
\hline & 4 & 31 & 1 & 219.2 & 4.5621 & $\begin{array}{l}16.219(2.289- \\
114.917)\end{array}$ & & \\
\hline
\end{tabular}

Association between weight change and occurrence of tuberculosis.

Based on the weight at the time of the national health examination from 2009 to 2010 , we analyzed whether change in weight compared to the national health examinations of the previous 4 years affects the occurrence of TB. Subjects who were underweight continuously had the highest incidence rate of TB, followed by those who became underweight due to weight loss for any reason. This association remained consistent after adjusting for demographic factors and underlying diseases (Table 4). 
Table 4

Association between weight change and occurrence of TB.

\begin{tabular}{|c|c|c|c|c|c|c|c|c|c|c|c|c|}
\hline $\begin{array}{l}\text { Weight } \\
\text { change }\end{array}$ & N. & TB & $\begin{array}{l}\text { Follow-up } \\
\text { Duration, } \\
\text { Person-year }\end{array}$ & $\begin{array}{l}\text { IR } \\
\text { per } \\
1000\end{array}$ & $\begin{array}{l}\text { Model } 1^{*} \text {, } \\
\text { HR } \\
(95 \% \mathrm{Cl})\end{array}$ & $\begin{array}{l}\mathrm{p}- \\
\text { value }\end{array}$ & $\begin{array}{l}\text { Model } 2^{\dagger} \\
\text { HR } \\
(95 \% \mathrm{Cl})\end{array}$ & $\begin{array}{l}\mathrm{p}- \\
\text { value }\end{array}$ & $\begin{array}{l}\text { Model } 3^{\ddagger} \text {, } \\
\text { HR } \\
(95 \% \mathrm{Cl})\end{array}$ & $\begin{array}{l}\mathrm{p}- \\
\text { value }\end{array}$ & $\begin{array}{l}\text { Model 4§, } \\
\text { HR } \\
(95 \% \mathrm{Cl})\end{array}$ & $\begin{array}{l}\mathrm{p}- \\
\text { value }\end{array}$ \\
\hline $\mathrm{No} / \mathrm{No}^{\mathrm{a}}$ & 2274478 & 835 & 16231908.2 & 0.51349 & $\begin{array}{l}1 \\
\text { (Reference) }\end{array}$ & $<0.001$ & $\begin{array}{l}1 \\
\text { (Reference) }\end{array}$ & $<0.001$ & $\begin{array}{l}1 \\
\text { (Reference) }\end{array}$ & $<0.001$ & 1(Reference) & $<0.00$ \\
\hline No/Yes ${ }^{b}$ & 29529 & 237 & 208208 & 1.13828 & $\begin{array}{l}2.214 \\
(1.946- \\
2.52)\end{array}$ & & $\begin{array}{l}2.727 \\
(2.395- \\
3.105)\end{array}$ & & $\begin{array}{l}2.657 \\
(2.334- \\
3.026)\end{array}$ & & $\begin{array}{l}2.611 \\
(2.292- \\
2.973)\end{array}$ & \\
\hline $\mathrm{Yes} / \mathrm{No}^{\mathrm{c}}$ & 35885 & 238 & 254106.21 & 0.93662 & $\begin{array}{l}1.822 \\
(1.602- \\
2.073)\end{array}$ & & $\begin{array}{l}2.359 \\
(2.071- \\
2.686)\end{array}$ & & $\begin{array}{l}2.327 \\
(2.044- \\
2.65)\end{array}$ & & $\begin{array}{l}2.304 \\
(2.023- \\
2.624)\end{array}$ & \\
\hline Yes/Yes $^{d}$ & 36542 & 512 & 399468.69 & 1.2817 & $\begin{array}{l}2.494 \\
(2.281- \\
2.726)\end{array}$ & & $\begin{array}{l}3.297 \\
(3.01- \\
3.612)\end{array}$ & & $\begin{array}{l}3.22 \\
(2.939- \\
3.527)\end{array}$ & & $\begin{array}{l}3.168 \\
(2.892- \\
3.471)\end{array}$ & \\
\hline
\end{tabular}

TB: tuberculosis; IR: incidence rate; HR: hazard ratio; Cl: confidence interval; DM: diabetes mellitus; HTN: hypertension; WC: waist circumference; MS: metabolic syndrome.

${ }^{*}$ Model 1: Non-adjusted.

${ }^{\dagger}$ Model 2: adjusted for age and sex.

‡ Model 3: adjusted for Model 1+ smoking, drinking and regular exercise.

$\S$ Model 4: adjusted for Model 2+diabetes mellitus, hypertension and dyslipidemia.

${ }^{\mathrm{a}} \mathrm{No} / \mathrm{No}$ : $\mathrm{BMI} \geq 18.5$ at the 1 st National health examination/BMI $\geq 18.5$ at the 4 th National health examination.

${ }^{\mathrm{b}} \mathrm{No} / \mathrm{Yes}: \mathrm{BMI} \geq 18.5$ at the $1 \mathrm{st}$ National health examination/BMI $<18.5$ at the 4 th National health examination.

${ }^{c}$ Yes/No: $\mathrm{BMI}<18.5$ at the $1 \mathrm{st}$ National health examination/BMI $\geq 18.5$ at the 4 th National health examination.

${ }^{d}$ Yes/Yes: BMI<18.5 at the 1 st National health examination/BMI $<18.5$ at the 4 th National health examination.

\section{Discussion}

In this large-scale, population-based, longitudinal study, we found that being underweight was associated with increased occurrence of TB. Subjects with a higher accumulated number of underweight also had a higher association with occurrence of TB.

Underweight has been shown to be associated with host susceptibility to TB in several studies. In a similar context, several studies have shown overweight people to have a lower incidence of $\mathrm{TB}^{4-10}$. Lee et al. explored the prevalence rate of active TB among homeless people who had poor nutrition and unsafe housing conditions in Seoul, Korea. In that study, underweight, defined as BMI <18.5, was an independent risk factor for active pulmonary TB ${ }^{4}$. Kim et al. evaluated the association between BMI and incidence of TB and showed that incident TB decreased as BMI increased after adjusting for age, sex, income, smoking, alcohol, and diabetes ${ }^{10}$. Badawi et al. performed systematic analysis of the relationship between obesity and TB and reported that the adjusted odds ratio of TB was 4.96 in underweight people and 0.26 in obese people ${ }^{8}$. Another systematic literature review found a strong and consistent log-linear inverse relationship between BMI and TB incidence in countries with a variety of TB burdens ${ }^{6}$. These studies were designed so that the subjects' body weight was assessed at a certain point in time, and that those subjects were followed for several years to observe whether TB develops. No data were collected on possible weight loss or gain during the follow-up period.

However, monitoring of weight history is important in health outcomes. Weight fluctuation or weight cycling can indicate difficulty maintaining homeostasis and reflect changes in body composition such as fat mass or lean mass. These changes in weight might be associated with increased risk of all-cause mortality, especially in older adults ${ }^{11-13}$.

Based on these studies, we further investigated whether the duration of underweight affects the occurrence of TB. We introduced the definition of accumulated number of underweight and investigated whether the occurrence of TB increased as accumulated number of underweight increased. In addition, we also checked whether there was a difference in occurrence of TB between those who gained weight and those who lost weight during the study period.

Our study found that the occurrence of TB was significantly higher among those who had been underweight for a long time. In subjects with decrease in weight compared to the result of a previous national health examination, the occurrence of TB was statistically significantly increased. These results were consistent even after all relevant factors were adjusted.

Underweight could be an indicator for undernutrition and a surrogate marker for frailty. It is well known that undernutrition is linked closely to cellular immune function. Nutrition regulates changes in immune cells, which alter immunity in terms of infection response in human studies $7,14-16$. The results of experiments 
aiming to identify the underlying mechanism of these changes point to defects in T cell recirculation and proliferation and diminished production of protective cytokines and anti-mycobacterial effector molecules $7,17,18$. Although the precise mechanisms by which undernutrition exerts these changes in immune cells are not fully understood, leptin appears to be associated with immune function. Leptin is an obesity hormone produced by adipocytes that acts as a neuroendocrine and immune mediator. It plays an important role in immune function by promoting differentiation to, and thereby increasing the number of, $T$ cells, which might reduce the risk of TB infection. In contrast, low plasma leptin in undernutrition was related to impairment of immune function, which might increase the risk of TB infection ${ }^{19,20}$. An animal study demonstrated that leptin-deficient mice had a higher risk of pulmonary TB infection ${ }^{21}$.

The strength of our study is that it is a nationwide, population-based study including a large study population of more than two million. Because of the high participation rate of national health examinations, there is a small possibility of selection bias, and the results of this study have high generalizability. In addition, the detailed personal data collected at baseline enabled us to stratify and adjust for relevant risk factors for TB. Furthermore, there was 1 year of time lag between the latest record of weight/BMI calculation and TB diagnosis based on ICD codes. In general, retrospective cohort studies have a limitation of not being able to determine cause-effect relationships, but by setting a time lag, the cause-effect relationship could be explained even in a retrospective study design. Moreover, because our study collected body weight over four years, we could evaluate the time-varying effect of underweight on occurrence of TB.

Although TB is significantly associated with malnutrition, especially in poorer countries or war-time conditions, this type of malnutrition does not occur or occurs in a very small fraction of the population in Korea ${ }^{7}$. Mild to moderate undernutrition can affect large fractions of the population at risk for TB in Korea. This risk relative to specific levels of undernutrition should be defined. Our study presented the concept of accumulated number of underweight and indirectly suggested the severity of the undernutrition condition through these numbers. Latent tuberculosis infection (LTBI) is considered a critical factor for high TB prevalence in Korea. Therefore, programmatic management of LTBI is one of the key strategies of national TB control programs, and LTBI management focusing on this strategy has expanded every year. The most important strategy of LTBI management is prioritization of the target population, those who were at high risk of developing $\mathrm{TB}^{22,23}$. Based on the results of this study, it is expected that LTBI treatment could be considered in those who have maintained low BMI for several years.

There are several limitations to our study. First, the universal validity of our results might be in question because almost all of our study subjects were Korean. The generalizability of our findings to other non-Asian ethnic groups requires further investigation. Second, we had no information about the effect of body composition. Lean mass and fat mass would have different effects on development of TB. However, BMI or underweight does not distinguish between adipose fat, muscle, bone, and water. To overcome this limitation, we performed stratified analysis according to WC and MS to minimize the effect of adiposity. Third, since an experimental study was not carried out, we could not elucidate the exact pathophysiology of the effect of duration of underweight on occurrence of TB. More research is needed to clarify the pathophysiology, focusing on TB and impairment of immune function according to accumulated number of underweight.

In conclusion, accumulated number of underweight had a statistically significant association with occurrence of TB even after adjusting for various independent factors.

\section{Methods}

Data source and study populations. In Korea, the Korean National Health Insurance Service (NHIS), a single insurer managed by the Korean government, provides a mandatory universal health insurance to $97 \%$ of the population. The NHIS provides free biennial national health examination programs, which include a general health examination for all citizens aged 40 and above and all employees older than 20 years.

These exams include anthropometric measurements (i.e., height, weight, and waist circumference [WC]); blood pressure (BP); laboratory measurements; and lifestyle information. The NHIS also keeps medical data, including diagnostic codes, procedures and operations, prescription drugs, and intractable diseases including cancer.

Our study used the health examination data and medical data from the NHIS. We included the data of people who received a health examination through the NHIS between 1 January 2009 and 31 December 2010, and who had received health examinations for four consecutive years prior to 2009. We excluded individuals with a prior diagnosis of TB during the 4 years prior to 2009, those with any missing variables, and those who were diagnosed with TB or died within one year after the national health examination. Included populations in the analysis were followed until 31 December 2017.

The present study protocol conformed to the ethical guidelines of the 1975 Declaration of Helsinki, as revised

in 1983. The Institutional Review Board (IRB) of Soongsil University approved this study (SSU-202007-HR-236-01). The IRB has approved a waiver of the requirement to obtain informed consent from research participants.

Measurement and definitions. During the national health examination, height, weight, and WC were measured. Body mass index (BMI) was calculated by dividing weight $(\mathrm{kg})$ by height $(\mathrm{m})$ squared and was classified as underweight ( $<18.5 \mathrm{~kg} / \mathrm{m} 2)$, normal to overweight (18.5-24.9 kg/m2), or obese ( $\geq 25$ $\mathrm{kg} / \mathrm{m} 2$ ) by $\mathrm{WHO}^{24,25}$. Accumulated number of underweight was defined as the number of times recorded as underweight at the national health examination during the four consecutive years prior to the health examination in 2009-2010. We investigated the accumulated number of underweight of the included population. Study populations responded to a standardized self-administered questionnaire regarding past medical history and lifestyle behaviors such as smoking, drinking, and physical activities. Smoking status was classified into never smoker, ex-smoker, and current smoker. Drinking was divided into none, mild ( $<30 \mathrm{~g}$ of alcohol/day), and heavy ( $\geq 30 \mathrm{~g} /$ day) drinking. Regular exercise was defined as moderate physical activity for more than 30 min more than 5 days per week over the previous week. The insurance premiums were determined by income level, and we defined the low-income group as subjects whose incomes would be less than the bottom 20 percent of the insured group.

Page $8 / 11$ 
Baseline co-morbidities included hypertension (HTN), diabetes mellitus (DM), and dyslipidemia. These diseases were defined using physician diagnosis or use of medication based on self-reporting. HTN was defined as systolic blood pressure (BP) $\geq 140 \mathrm{mmHg}$, diastolic BP $\geq 90 \mathrm{mmHg}$, or use of antihypertensive drugs with a prior diagnosis (International Classification of Diseases, Tenth Revision, Clinical Modification [ICD-10-CM] codes I10-13, I15). BP was measured after the subjects had been seated for $5 \mathrm{~min}$ with the arm in the appropriate position. Similarly, DM was defined as a prior diagnosis (ICD-10-CM codes E11-14) and treatment with glucose-lowering agents or as overnight fasting plasma glucose $\geq 126 \mathrm{mg} / \mathrm{dL}$. Dyslipidemia was defined as a prior diagnosis (ICD-10-CM code E78) and treatment with statins or as total cholesterol $\geq 240 \mathrm{mg} / \mathrm{dL}$. Definition of WC in metabolic syndrome (MS) which reflects abdominal obesity was that $W C \geq 90 \mathrm{~cm}$ for men, or $\geq 85 \mathrm{~cm}$ for women 26,27 .

Study outcomes and follow-up. The primary outcome of the study was occurrence of newly diagnosed TB according to accumulated number of underweight. The NHIS provided additional insurance coverage for all patients diagnosed with cancer and some intractable diseases such as TB to enhance benefit coverage from the year 2010. Specific insurance codes were applied mandatorily to patients with TB after confirmation of diagnosis ${ }^{28,29}$. The cohort was followed from 1 year after the health examination date to the date of occurrence of TB or until the end of the study period (31 December 2017). The secondary outcome of the study was the occurrence of newly diagnosed TB according to weight change.

Statistical analysis. Continuous variables were presented as mean \pm standard deviation, and categorical variables were presented as number (\%).Values were compared using the one-way analysis of variance test for continuous variables and the $\chi 2$ test for categorical variables. The cumulative incidence probability of all-cause mortality was estimated using the Kaplan-Meier method, and between-group comparisons of the resulting curves were subjected to a univariate analysis via the log-rank test. Cox proportional hazards analyses were performed to evaluate the association of accumulated number of underweight with occurrence of TB, and the associations were calculated as hazard ratio (HR) and 95\% confidence interval (Cl). A multivariable-adjusted proportional hazards model was applied: (1) Model 1 was unadjusted; (2) Model 2 was adjusted for age and sex; (3) Model 3 was additionally adjusted for smoking, drinking, and regular exercise; and (4) Model 4 was further adjusted for DM, HTN, and dyslipidemia. In addition, stratified analysis according to sex, age, presence of DM, presence of HTN, and WC in MS was performed because these factors have a significant impact on TB. Statistical analyses were conducted using SAS software (Version 9.4; SAS Institute, Cary, NC, USA), and a P-value $<0.05$ was considered statistically significant.

\section{Declarations}

\section{Author contributions}

G.E.P.,H.J.K., and K.D.H. conceived the presented idea. K.D.H. collected the study data and did the statistical analyses. G.E.P. wrote the initial draft of the paper. G.E.P.Y.H.E., H.K.K. and H.J.K. reviewed the manuscript. H.J.K. and K.D.H. supervised the manuscript and act as senior author. All authors approved the paper

\section{Competing interests}

The authors declare no competing interests.

\section{References}

1. World Health Organization. Global tuberculosis report 2018 (World Health Organization, 2018).

2. Kim, H. R. et al. [Notified Tuberculosis in the Republic of Korea, 2018]. https://www.kdca.go.kr/board/board.es? mid=a20602010000\&bid=0034\&list_no=143392\&act=view (2018).

3. Cho, K. S. Tuberculosis control in the Republic of Korea. Epidemiol. Health 40, e2018036, http://doi.org/10.4178/epih.e2018036 (2018).

4. Lee, C. H. et al. Active pulmonary tuberculosis and latent tuberculosis infection among homeless people in Seoul, South Korea: a cross-sectional study. BMC Public Health 13, 720, http://doi.org/10.1186/1471-2458-13-720 (2013).

5. Tverdal, A. Body mass index and incidence of tuberculosis. Eur. J. Respir. Dis. 69, 355-362 (1986).

6. Lonnroth, K., Williams, B. G., Cegielski, P. \& Dye, C. A consistent log-linear relationship between tuberculosis incidence and body mass index. Int. J. Epidemiol. 39, 149-155, http://doi.org/10.1093/ije/dyp308 (2010).

7. Cegielski, J. P. \& McMurray, D. N. The relationship between malnutrition and tuberculosis: evidence from studies in humans and experimental animals. Int. J. Tuberc. Lung Dis. 8, 286-298 (2004).

8. Badawi, A., Gregg, B. \& Vasileva, D. Systematic analysis for the relationship between obesity and tuberculosis. Public Health 186, 246-256, http://doi.org/10.1016/j.puhe.2020.06.054 (2020).

9. Semunigus, T., Tessema, B., Eshetie, S. \& Moges, F. Smear positive pulmonary tuberculosis and associated factors among homeless individuals in Dessie and Debre Birhan towns, Northeast Ethiopia. Ann. Clin. Microbiol. Antimicrob. 15, 50, http://doi.org/10.1186/s12941-016-0165-x (2016).

10. Kim, S. J., Ye, S., Ha, E. \& Chun, E. M. Association of body mass index with incident tuberculosis in Korea. PLoS One 13, e0195104, http://doi.org/10.1371/journal.pone.0195104 (2018).

11. Arnold, A. M., Newman, A. B., Cushman, M., Ding, J. \& Kritchevsky, S. Body weight dynamics and their association with physical function and mortality in older adults: the Cardiovascular Health Study. J. Gerontol. A Biol. Sci. Med. Sci. 65, 63-70, http://doi.org/10.1093/gerona/glp050 (2010).

Page $9 / 11$ 
12. Zhang, Y. et al. The association between weight fluctuation and all-cause mortality: A systematic review and meta-analysis. Medicine (Baltimore) 98, e17513, http://doi.org/10.1097/MD.0000000000017513 (2019).

13. Murphy, R. A. et al. Weight change, body composition, and risk of mobility disability and mortality in older adults: a population-based cohort study. J. Am. Geriatr. Soc. 62, 1476-1483, http://doi.org/10.1111/jgs.12954 (2014).

14. Alwarawrah, Y., Kiernan, K. \& Maclver, N. J. Changes in Nutritional Status Impact Immune Cell Metabolism and Function. Front. Immunol. 9, 1055, http://doi.org/10.3389/fimmu.2018.01055 (2018).

15. Falagas, M. E. \& Kompoti, M. Obesity and infection. Lancet Infect. Dis. 6, 438-446, http://doi.org/10.1016/S1473-3099(06)70523-0 (2006).

16. Rytter, M. J., Kolte, L., Briend, A., Friis, H. \& Christensen, V. B. The immune system in children with malnutrition-a systematic review. PLoS One 9 , e105017, http://doi.org/10.1371/journal.pone.0105017 (2014).

17. Dai, G., Phalen, S. \& McMurray, D. N. Nutritional modulation of host responses to mycobacteria. Front. Biosci. 3, e110-122, http://doi.org/10.2741/a371 (1998).

18. McMurray, D. N., Bartow, R. A. \& Mintzer, C. L. Impact of protein malnutrition on exogenous reinfection with Mycobacterium tuberculosis. Infect. Immun. 57, 1746-1749, http://doi.org/10.1128/iai.57.6.1746-1749.1989 (1989).

19. Palacio, A., Lopez, M., Perez-Bravo, F., Monkeberg, F. \& Schlesinger, L. Leptin levels are associated with immune response in malnourished infants. J. Clin. Endocrinol. Metab. 87, 3040-3046, http://doi.org/10.1210/jcem.87.7.8636 (2002).

20. La Cava, A. \& Matarese, G. The weight of leptin in immunity. Nat. Rev. Immunol. 4, 371-379, http://doi.org/10.1038/nri1350 (2004).

21. Wieland, C. W. et al. Pulmonary Mycobacterium tuberculosis infection in leptin-deficient ob/ob mice. Int. Immunol. 17, 1399-1408, http://doi.org/10.1093/intimm/dxh317 (2005).

22. Jeon, D. Latent tuberculosis infection: recent progress and challenges in South Korea. Korean J. Intern. Med. 35, 269-275, http://doi.org/10.3904/kjim.2020.029 (2020).

23. Rangaka, M. X. et al. Controlling the seedbeds of tuberculosis: diagnosis and treatment of tuberculosis infection. Lancet 386, 2344-2353, http://doi.org/10.1016/S0140-6736(15)00323-2 (2015).

24. Obesity: preventing and managing the global epidemic. Report of a WHO consultation. World Health Organ. Tech. Rep. Ser., i-xii, 1-253 (2000).

25. World Health Organization \& Regional Office for the Western Pacific. The Asia-Pacific perspective : redefining obesity and its treatment (Health Communications Australia, 2000).

26. Alberti, K. G. et al. Harmonizing the metabolic syndrome: a joint interim statement of the International Diabetes Federation Task Force on Epidemiology and Prevention; National Heart, Lung, and Blood Institute; American Heart Association; World Heart Federation; International Atherosclerosis Society; and International Association for the Study of Obesity. Circulation 120, 1640-1645, http://doi.org/10.1161/CIRCULATIONAHA.109.192644 (2009).

27. Lee, S. Y. et al. Appropriate waist circumference cutoff points for central obesity in Korean adults. Diabetes Res. Clin. Pract. 75, 72-80, http://doi.org/10.1016/j.diabres.2006.04.013 (2007).

28. Cheol Seong, S. et al. Data Resource Profile: The National Health Information Database of the National Health Insurance Service in South Korea. Int. J. Epidemiol. 46, 799-800, http://doi.org/10.1093/ije/dyw253 (2017).

29. Park, S. et al. Association of CKD with Incident Tuberculosis. Clin. J. Am. Soc. Nephrol.14, 1002-1010, http://doi.org/10.2215/CJN.14471218 (2019).

\section{Figures}



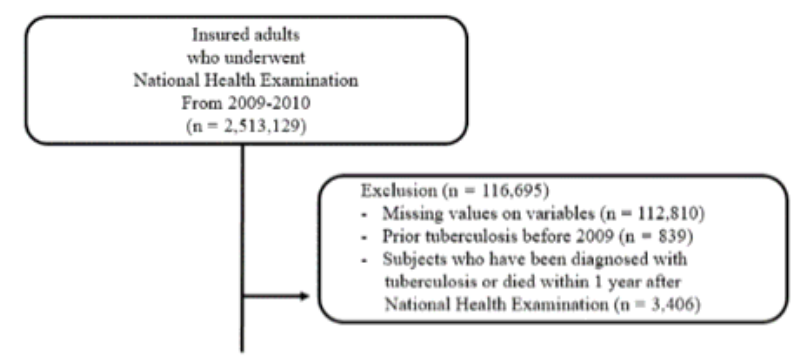

$2,396,434$ of study populations
$(\mathrm{n}=2,396,434)$

$\downarrow$

Aceumulated number of being underweight

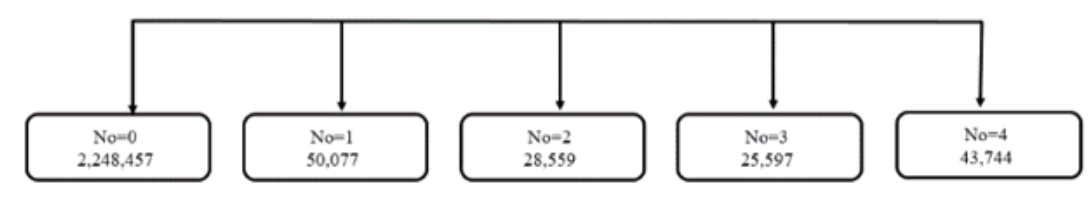

Figure 1

\section{Study population.}
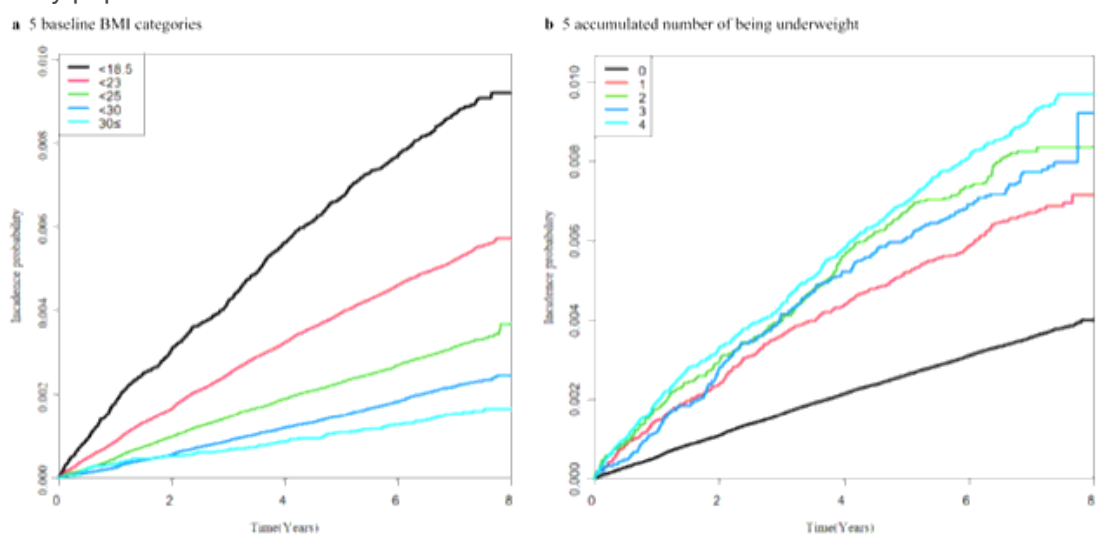

Figure 2

Kaplan-Meier estimation of the cumulative incidence probability of TB. The analyses are stratified by (a) 5 baseline BMI categories and (b) 5 accumulated number of being underweight. 